Supplement of Atmos. Chem. Phys., 14, 12195-12207, 2014

http://www.atmos-chem-phys.net/14/12195/2014/

doi:10.5194/acp-14-12195-2014-supplement

(C) Author(s) 2014. CC Attribution 3.0 License.

(c) (1)

Atmospheric

Chemistry

and Physics

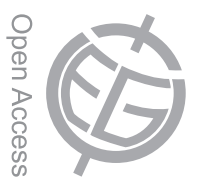

Supplement of

\title{
OH-initiated heterogeneous oxidation of tris-2-butoxyethyl phosphate: implications for its fate in the atmosphere
}

Y. Liu et al.

Correspondence to: J. Liggio (john.liggio@ec.gc.ca) 


\section{Supporting information.}

\section{Mass transfer diffusion model.}

From Fick's first law of diffusion, the rate of change of mass of a single, spherical, homogeneous drop of compound $A$ can be described with

$\frac{\mathrm{d} m}{\mathrm{~d} t}=4 \pi R^{2} D_{\mathrm{v}} \frac{\mathrm{d} \rho_{\mathrm{v}}}{\mathrm{d} R} \quad$ Eq. $(\mathrm{S} 1)$

where $m$ is the mass of the drop $(\mathrm{g}), R$ is the radial distance from the center of the drop (cm), $D_{\mathrm{v}}$ is the molecular diffusion coefficient of $A$ in air $\left(\mathrm{cm}^{2} \mathrm{~s}^{-1}\right), \rho \mathrm{v}$ is the density of the vapor of $\mathrm{A}\left(\mathrm{g} \mathrm{cm}^{-3}\right)$, and $\mathrm{d} \rho \mathrm{v} / \mathrm{d} R$ is the radial gradient of vapor density. When latent heat is taken into consideration during evaporation, Eq. (S1) becomes

$\frac{\mathrm{d} m}{\mathrm{~d} t}=\frac{4 \pi D_{\mathrm{V}}\left(p_{\mathrm{V}}-p_{\mathrm{V}, \mathrm{s}}\right)}{\frac{D_{\mathrm{V}} L_{\mathrm{e}} p_{\mathrm{V}, \mathrm{S}}}{k_{\mathrm{a}} T}\left(\frac{L_{\mathrm{e}}}{R_{\mathrm{V}} T}-1\right)+R_{\mathrm{V}} T} \quad$ Eq. $(\mathrm{S} 2)$

Where $p_{\mathrm{v}}$ and $p_{\mathrm{v}, \mathrm{s}}$ is the vapor pressure of $A$ in bulk gas phase and on the particle surface, respectively $(\mathrm{Pa}), L_{\mathrm{e}}$ is the latent heat of evaporation of $A\left(\mathrm{~J} \mathrm{~g}^{-1}\right), \kappa_{\mathrm{a}}$ is the thermal conductivity of moist air $\left(\mathrm{J} \mathrm{cm}^{-1} \mathrm{~s}^{-1} \mathrm{~K}^{-1}\right), R_{\mathrm{v}}$ is ideal gas constant $\left(8.314 \mathrm{~J} \mathrm{~K}^{-1} \mathrm{~mol}^{-1}\right)$. Details regarding the derivation are also given elsewhere (Jacobson, 2005). According to a partition model (Kroll and Seinfeld, 2008;Pankow, 1994), the vapor pressure of $A$ in bulk gas phase is calculated as

$p_{\mathrm{v}}=\frac{R_{\mathrm{v}} T \rho_{\mathrm{T}} \rho_{\mathrm{v}, \mathrm{s}}}{M+\rho_{\mathrm{v}, \mathrm{s}}}$

Where $\rho_{\mathrm{T}}$ is the total density of $A$ in both gas and particle phase $\left(\mathrm{g} \mathrm{cm}^{-3}\right)$, and $M$ is the mass loading of organic aerosol in the atmosphere $\left(\mathrm{g} \mathrm{cm}^{-3}\right)$. Both curvature and solute effects are corrected for $p_{\mathrm{v}}$ and $p_{\mathrm{v}, \mathrm{s}}$. The Molecular diffusion coefficient $\left(D_{\mathrm{v}}\right)$ for OPEs 
and OA are calculated and corrected according to (Jacobson, 2005).

Internally mixed particles (OPEs-OA) are considered an ideal solution for OPEs. The evaporation of OA and OPEs are treated separately in this model. Then, the mass of the drop in each step is calculated by
$m_{i+1}=m_{i}+d m_{i}$
Eq. (S4)

Where, $\mathrm{i}=0,1,2 \ldots$

The evaporation rate constant $\left(k_{\mathrm{e}}\right)$ of the OPE is obtained from the slope of the plot of $\ln \left(c_{\mathrm{OPE}} / c_{\mathrm{OPE}, 0}\right)$ against $t$. The following parameters are used as inputs in to the model.

Table S1 Inputs for the evaporation rate calculation.

\begin{tabular}{llll}
\hline & TBEP & OA & Air \\
\hline$\rho\left(\mathrm{g} \mathrm{cm}^{-3}\right)$ & $1.02^{\mathrm{a}}$ & $1.27^{\mathrm{b}}$ & $1.18 \times 10^{-3 \mathrm{c}}, 0.33^{\mathrm{d}}$ \\
$\mu\left(\mathrm{kg} \mathrm{m}^{-1} \mathrm{~s}^{-1}\right)$ & - & - & $1.86 \times 10^{-5} \mathrm{e}$ \\
Vapor pressure $(\mathrm{Pa})$ & $3.3 \times 10^{-6 \mathrm{f}}$ & $3.3 \times 10^{-7} \mathrm{~g}$ & - \\
$M\left(\mathrm{~g} \mathrm{~mol}^{-1}\right)$ & 398 & $300^{\mathrm{h}}$ & 29 \\
$m_{0}\left(\mu \mathrm{g} \mathrm{m}^{-3}\right)$ & $1.0 \times 10^{-3}$ & $5.0^{\mathrm{h}}$ & - \\
$D_{\mathrm{v}}\left(\mathrm{cm}^{2} \mathrm{~s}^{-1}\right)$ & 0.1617 & 0.1635 & - \\
$P(\mathrm{~Pa})$ & & \multicolumn{2}{c}{101325} \\
$\mathrm{~T}(\mathrm{~K})$ & & 298 \\
\hline
\end{tabular}

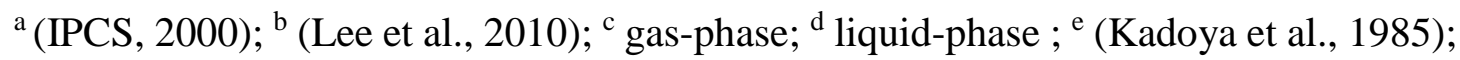

${ }^{\text {f }}$ (Bergman et al., 2012); ${ }^{\mathrm{g}}$ (Abramson et al., 2013); ${ }^{\text {h }}$ (Vogel et al., 2013). 


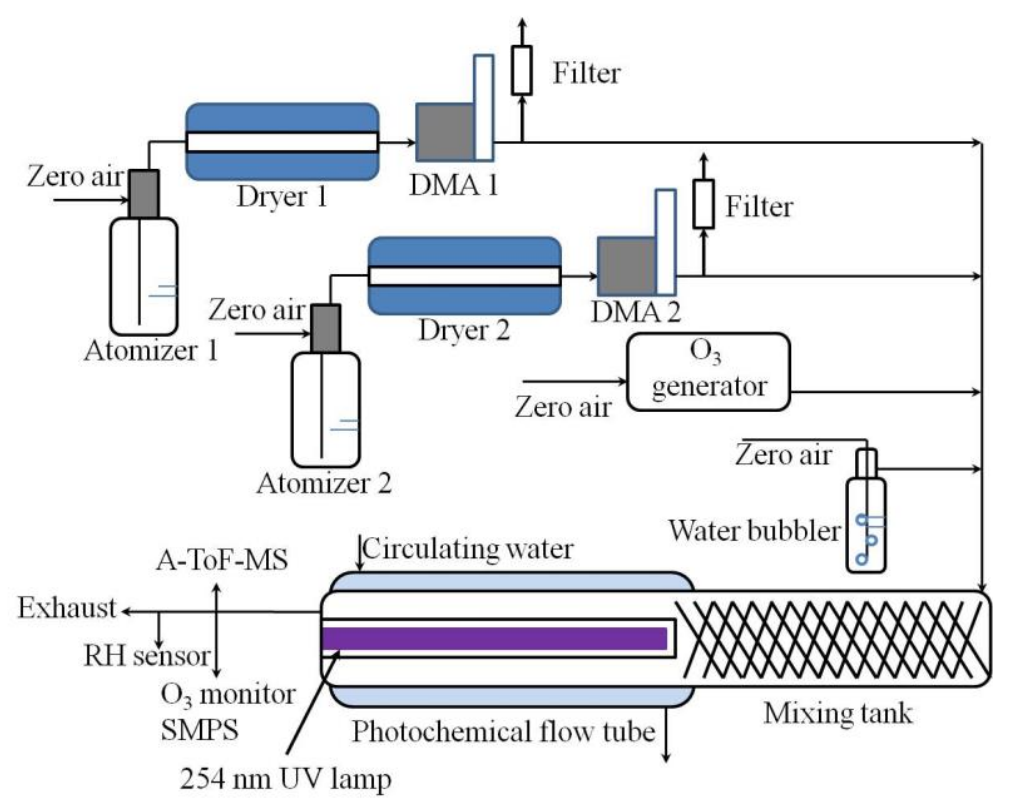

Figure S1. Experimental schematic for heterogeneous oxidation studies

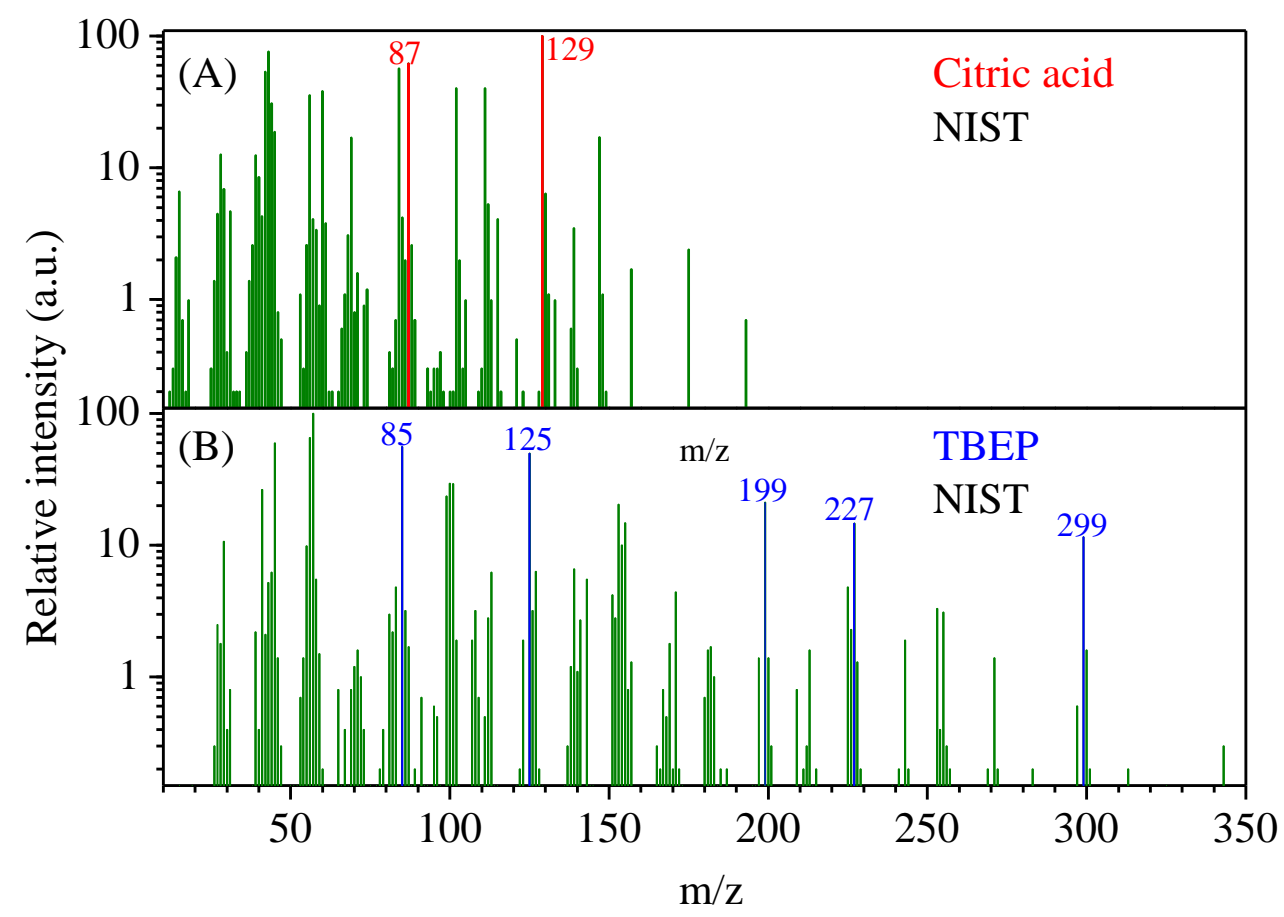

Figure S2. NIST mass spectra of (A) citric acid (B) TBEP. 


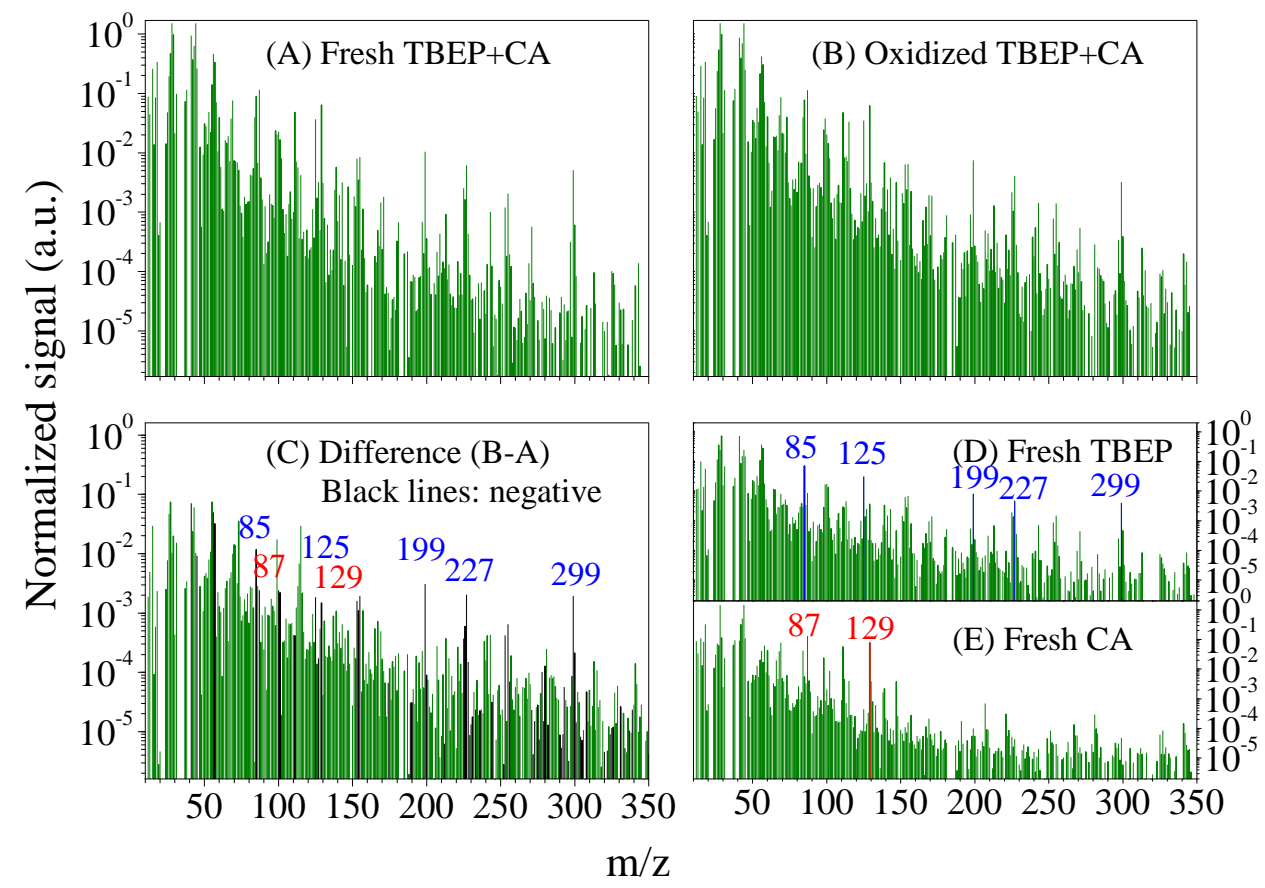

Figure S3. (A) Mass spectra of unreacted, (B) oxidized and (C) difference mass spectra for externally mixed TBEP and CA; (D) and (E) mass spectra of unreacted TBEP and CA. 


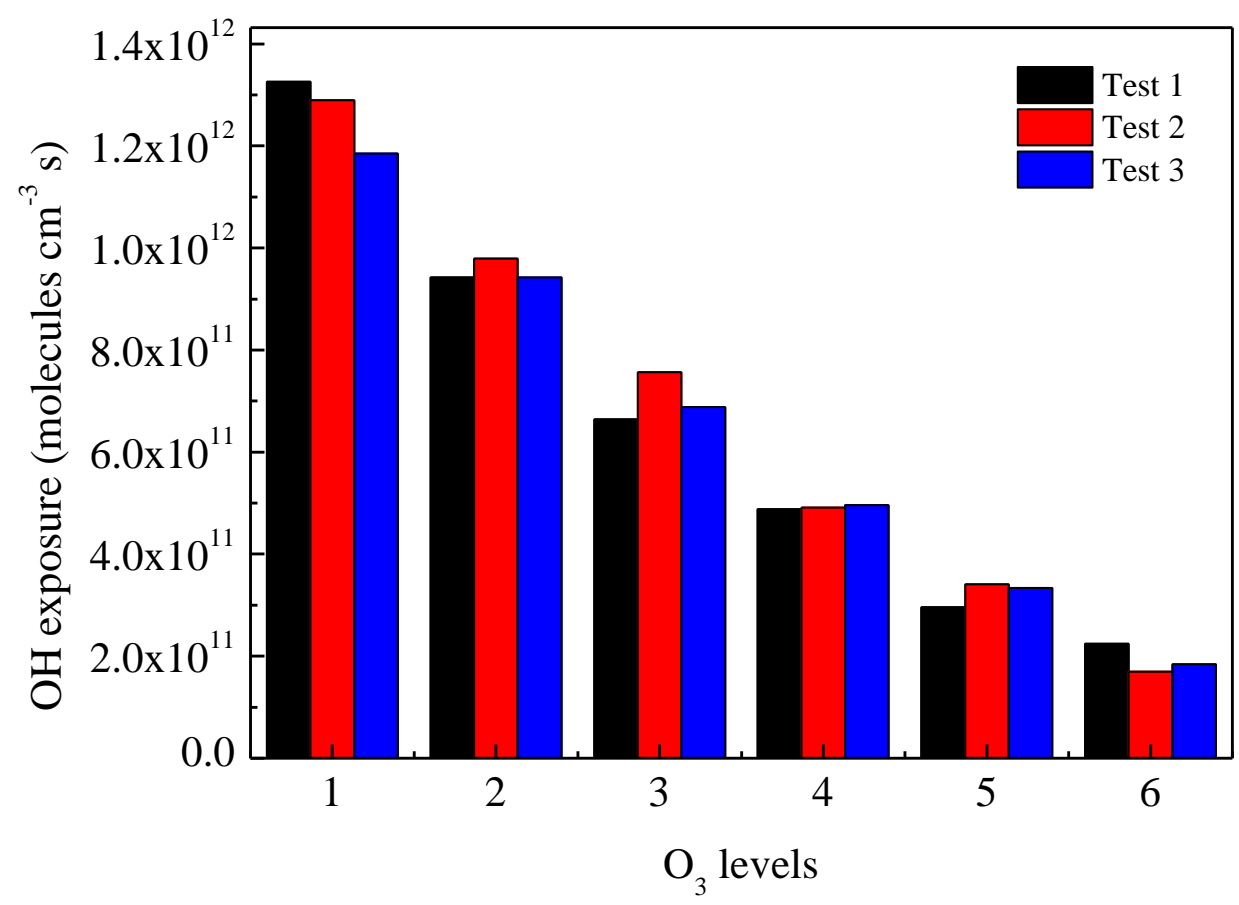

Figure S4. Repeatability of $\mathrm{OH}$ exposures under the identical experimental conditions.

$\mathrm{OH}$ concentrations were calibrated with methanol as a reference compound. The gas flow rate is $1.03 \mathrm{~L} \mathrm{~min}^{-1}$ and the $\mathrm{RH}$ is $40 \pm 2 \%$. 

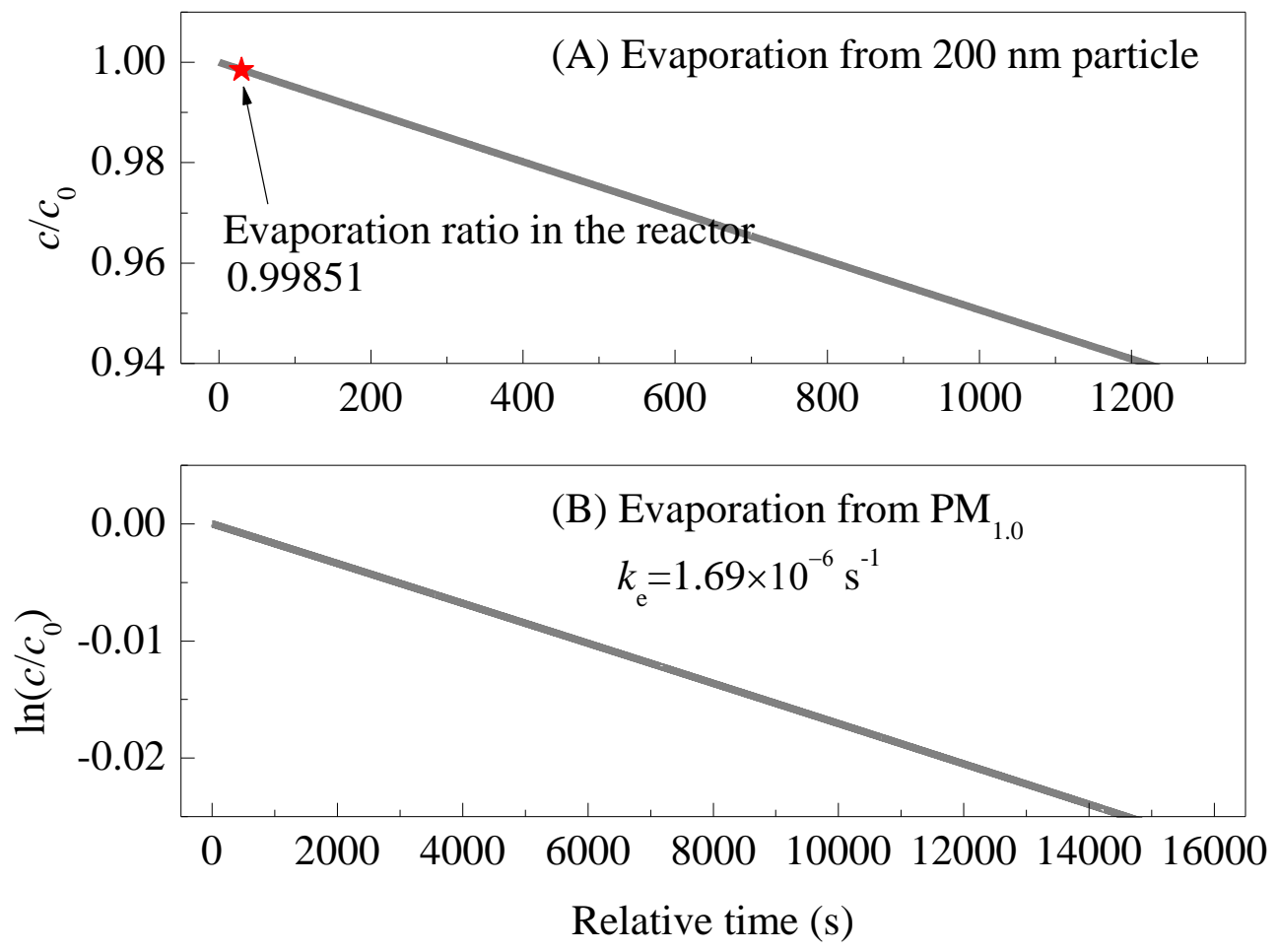

Figure S5. Calculated evaporation curves of TBEP from (A) $200 \mathrm{~nm}$ particles for laboratory experiment, and (B) ambient $\mathrm{PM}_{1.0}$.

\section{Reference:}

Abramson, E., Imre, D., Beranek, J., Wilson, J., and Zelenyuk, A.: Experimental determination of chemical diffusion within secondary organic aerosol particles, Phys. Chem. Chem. Phys., 15, 2983-2991, 10.1039/c2cp44013j, 2013.

Bergman, Å., Rydén, A., Law, R. J., de Boer, J., Covaci, A., Alaee, M., Birnbaum, L., Petreas, M., Rose, M., Sakai, S., Van den Eede, N., and van der Veen, I.: A novel abbreviation standard for organobromine, organochlorine and organophosphorus flame retardants and some characteristics of the chemicals, Environ. Int., 49, 57-82, 2012.

IPCS: (International Programme on Chemical Safety). Flame retardants: Tri(2-butoxyethyl) phosphate, tris(2-ethylhexyl) phosphate and tetrakis(hydroxymethyl) phosphonium salts, Environmental Health Criteria . 218, Geneva, Switzerland: World Health Organization, 2000.

Jacobson, M. Z.: Fundamentals of atmospheric modeling, Cambridge University Press, 2005.

Kadoya, K., Matsunaga, N., and Nagashima, A.: Viscosity and thermal conductivity of dry air in the gaseous phase, J. Phys. Chem. Ref. Data, 14, 947-970, 1985. 
Kroll, J. H., and Seinfeld, J. H.: Chemistry of secondary organic aerosol: Formation and evolution of low-volatility organics in the atmosphere, Atmos. Environ., 42, 3593-3624, 2008.

Lee, B. H., Kostenidou, E., Hildebrandt, L., Riipinen, I., Engelhart, G. J., Mohr, C., DeCarlo, P. F., Mihalopoulos, N., Prevot, A. S. H., Baltensperger, U., and Pandis, S. N.: Measurement of the ambient organic aerosol volatility distribution: application during the Finokalia Aerosol Measurement Experiment (FAME-2008), Atmos. Chem. Phys., 10, 12149-12160, 10.5194/acp-10-12149-2010, 2010.

Pankow, J. F.: An absorption-model of gas-particle partitioning of organic compounds in the atmosphere, Atmos. Environ., 28, 185-188, 1994.

Vogel, A. L., Äijälä, M., Corrigan, A. L., Junninen, H., Ehn, M., Petäjä, T., Worsnop, D. R., Kulmala, M., Russell, L. M., Williams, J., and Hoffmann, T.: In situ submicron organic aerosol characterization at a boreal forest research station during HUMPPA-COPEC 2010 using soft and hard ionization mass spectrometry, Atmos. Chem. Phys., 13, 10933-10950, 10.5194/acp-13-10933-2013, 2013. 